\title{
内蒙古半干旱草原土壤水分对降水格局变化的响应
}

\author{
陈敏玲 ${ }^{1,2} \quad$ 张兵伟 ${ }^{1,2} \quad$ 任婷婷 $^{1} \quad$ 王姗姗 $^{1,2} \quad$ 陈世苹 ${ }^{*}$ \\ ${ }^{1}$ 中国科学院植物研究所植被与环境变化国家重点实验室, 北京 $100093{ }^{2}{ }^{2}$ 中国科学院大学生命科学学院, 北京 100049
}

摘 要 在全球气候变化背景下, 未来我国北方半干旱地区的降水格局将呈现出季节与年际间降水波动增强和极端降水事 件增加的趋势。水分是半干旱草原的主要限制因子, 降水格局变化导致的土壤水分状况的改变必然对生态系统的结构和功能 产生显著的影响。该研究选取内蒙古多伦和锡林浩特两个典型半干旱草原群落, 通过分析2006-2013年的降水和多层次土壤 (0-10 cm, $10 \mathrm{~cm}, 20 \mathrm{~cm}, 30 \mathrm{~cm}$ 和 $50 \mathrm{~cm}$ )含水量连续观测数据, 研究降水格局变化对土壤水分状况及其垂直分布的影响, 特别 是土壤水分对降水事件的脉冲响应过程。结果表明：两个站点的土壤含水量均呈现显著的季节及年际间波动，其中土壤表层 0-10 cm水分波动更剧烈。锡林浩特 $50 \mathrm{~cm}$ 处土壤含水量波动较大, 主要由于春季融雪的影响。年际间多伦和锡林浩特生长季 土壤表层0-10 cm土壤含水量与降水量存在显著的正相关关系, 下层 $(10-50 \mathrm{~cm})$ 土壤含水量与降水量相关性不显著。研究发现 小至 $2 \mathrm{~mm}$ 的降水事件就能够引起两个站点表层0-10 cm 土壤含水量的升高, 即该地区有效降水为日降水量 $>2 \mathrm{~mm}$ 。表层 0-10 $\mathrm{cm}$ 土壤含水量对独立降水事件的脉冲响应可通过指数方程很好地拟合。降水事件的大小决定了降水后表层 $0-10 \mathrm{~cm}$ 土壤含水 量的最大增量和持续时间，同时这个脉冲响应过程还受到降水前土壤含水量的影响，但该过程中并未发现植被因子(叶面积 指数)的显著影响。降水后水分下渗深度及该深度的土壤含水量增量主要由降水事件的大小主导, 同时受到降水前土壤含水 量的影响。在多伦和锡林浩特, 平均每增加 $1 \mathrm{~mm}$ 降水, 下渗深度分别增加 1.06 和 $0.79 \mathrm{~cm}$ 。由此作者认为, 在内蒙古半干旱草 原，降水事件大小和降水前土壤干湿状况是影响土壤水分对降水响应的主要因素，而植被因子的影响较小。

关键词＼cjkstart降水事件；降水格局; 脉冲响应; 半干旱草原；土壤水分

引用格式: 陈敏玲, 张兵伟, 任婷婷, 王姗姗, 陈世苹 (2016). 内蒙古半干旱草原土壤水分对降水格局变化的响应. 植物生态学报, 40, 658-668. doi: 10.17521/cjpe.2015.0155

\section{Responses of soil moisture to precipitation pattern change in semiarid grasslands in Nei Mongol, China}

CHEN Min-Ling ${ }^{1,2}$, ZHANG Bing-Wei ${ }^{1,2}$, REN Ting-Ting ${ }^{1}$, WANG Shan-Shan ${ }^{1,2}$, and CHEN Shi-Ping ${ }^{1 *}$

${ }^{1}$ State Key Laboratory of Vegetation and Environmental Change, Institute of Botany, Chinese Academy of Sciences, Beijing 100093, China; and ${ }^{2}$ College of Life Sciences, University of Chinese Academy of Sciences, Beijing 100049, China

\section{Abstract}

Aims Under global climate change, precipitation patterns were predicted to change with larger seasonal and annual variations and more extreme events in the semiarid regions of northern China. Water availability is one of the key limited factors in semiarid grasslands. Changes in precipitation patterns will inevitably affect ecosystem structure and function through soil water condition. Our objective was to investigate the response of soil water content to changes of precipitation pattern, especially its pulse response to precipitation events.

Methods Two semiarid steppe sites (Duolun and Xilinhot) in Nei Mongol were chosen and meteorological stations were installed to monitor precipitation and soil volumetric water content $(V W C)$ at five soil depths $(0-10 \mathrm{~cm}$, $10 \mathrm{~cm}, 20 \mathrm{~cm}, 30 \mathrm{~cm}, 50 \mathrm{~cm}$ ) from 2006 to 2013. The pulse response of $V W C$ at $0-10 \mathrm{~cm}$ to an individual precipitation event was simulated by an exponential equation.

Important findings Significant seasonal and inter-annual variations of VWC were observed at the Duolun and Xilinhot sites. VWC at $50 \mathrm{~cm}$ soil layer in Xilinhot showed an obvious increase during the early spring due to the influences of snow melting. Mean surface (0-10 cm soil layer) VWC was significantly correlated with annual precipitation across eight years, but $V W C$ in the deeper soil layers $(10-50 \mathrm{~cm})$ were not impacted by precipitation. We also found that the precipitation event larger than $2 \mathrm{~mm}$ could induce a significant increase in surface $(0-10 \mathrm{~cm}$ soil layer) $V W C$, and could be regarded as an effective precipitation in this region. The maximum increment of 
surface $V W C$ after the events and lasting time ( $\left.T_{\text {lasting }}\right)$ were determined by the event size, while showed negatively linear correlations with the initial soil water content before the events. Vegetation development (leaf area index) did not show significant impacts on the responses of surface soil moisture to precipitation pulses. The infiltration depth of rain water was also determined by rain size and pre-event soil moisture. In average, soil water can infiltrate $1.06 \mathrm{~cm}$ and $0.79 \mathrm{~cm}$ deeper in Duolun and Xilinhot with $1 \mathrm{~mm}$ more precipitation, respectively. Therefore, our results suggest that the event size and pre-event soil moisture were the most important factors affecting response patterns of soil moisture to rain events in semiarid ecosystems.

Key words precipitation events; precipitation patterns; pulse responses; semiarid grassland; soil moisture

Citation: Chen ML, Zhang BW, Ren TT, Wang SS, Chen SP (2016). Responses of soil moisture to precipitation pattern change in semiarid grasslands in Nei Mongol, China. Chinese Journal of Plant Ecology, 40, 658-668. doi: 10.17521/cjpe.2015.0155

降水格局变化是全球气候变化的重要内容, 包 括降水量的变化、降水季节分布的变化, 以及降水 间隔的变化。许多大气环流模型都预测未来全球降 水格局会发生重大改变(IPCC, 2013)。据预测, 全球 气候变化将导致我国北方地区在未来100年内降水 增加30-100 mm (Ni \& Zhang, 2000); 同时还伴随着 降水间隔增大、小降水事件减少和极端降水事件增 加的趋势(Groisman et al., 1999; Easterling et al., 2000; Westra et al., 2014)。降水格局的变化最终会影 响生态系统结构和功能(Knapp et al., 2002; Yahdjian \& Sala, 2006)。

降水对生态系统的影响主要通过土壤水分的变 化来实现, 土壤水分的变化进一步调控生态系统的 结构和功能(Harper et al., 2005; Fay et al., 2011)。 Knapp等(2002)对一个北美湿润草原连续4年的降水 格局控制实验发现: 决定地上净初级生产力的是表 层土壤水分的季节变异, 而非季节平均值。这种变 异主要是由于降水事件的不连续及其后的干旱间隔 不一致导致(Huxman et al., 2004; Williams et al., 2009)。一般情况下, 降水发生之后, 土壤含水量会 快速增加, 然后由于植物蒸腾利用及土壤表面蒸发 而逐渐降低(Liu et al., 2002), 除非被另一个降水事 件所打断, 这一过程称为土壤含水量对降水事件的 脉冲响应(Huxman et al., 2004)。目前关于这种间断 的降水事件对生态系统过程和功能的影响已有不少 研究 (Liu et al., 2002; Weltzin \& Tissue, 2003; Huxman et al., 2004; Potts et al., 2006; Chen et al., 2009), 但对与之相应的土壤含水量的脉冲响应过 程却还很少进行深入的研究, 这在机制上限制了我 们对生态系统响应过程的理解。

在干旱半干旱地区，水分是主要的限制因子, 而降水是这些地区的主要甚至是唯一的水分获得途
径。同时干旱半干旱地区的降水格局也表现出降水 的季节和年际变异大, 小降水事件占主导但对降水 总量的贡献小, 大降水事件较少但对生态系统的影 响大等特征(Huxman et al., 2004)。在这一地区，草 原是主要的植被类型, 其面积占陆地自然植被面积 的32\% (Adams et al., 1990)。在我国，草原占国土面 积的 $41 \%$ (陈佐忠和汪诗平, 2000)。与其他生态系统 相比, 半干旱草原生态系统对水分的变化更为敏感 (Knapp \& Smith, 2001), 对资源可利用性的瞬时波 动响应更大(Blair, 1997)。研究土壤水分对降水格局 变化的响应有助于更深入地理解和解释未来降水格 局变化对我国干旱半干旱生态系统关键过程的影 响。本研究以我国内蒙古半干旱草原多伦和锡林浩 特两个研究站点8年(2006-2013)连续观测数据为基 础, 分析降水格局变化对土壤含水量在不同时间尺 度及其垂直分布的影响, 以期为理解干旱半干旱生 态系统对降水事件的响应提供理论基础。

\section{1 研究区域概况}

本研究选择了内蒙古锡林郭勒草原的多伦和锡 林浩特两个站点。多伦县位于内蒙古锡林郭勒盟东 南端, 属于中温带半干旱大陆性气候, 土壤类型主 要是栗钙土。年降水量 $380 \mathrm{~mm}$ (1952-2012年), 其中 生长季(5-9月)降水占全年降水量的88\%, 降水主要 发生在6-8月。年平均气温 $2.2{ }^{\circ} \mathrm{C}$, 生长季长约 150 天。本研究所选择的样地位于多伦县十三里滩, 该 样地于2001年作为长期研究样地围封, 围封前为自 由放牧草场。植被类型属于典型草原, 优势植物主 要有冷蒿(Artemisia frigida)和克氏针茅(Stipa krylovii)等。

锡林浩特位于内蒙古高原典型的半干旱草原地 区, 在多伦县以北约 $240 \mathrm{~km}$ 处。气候属于温带大陆 
性半干旱气候, 土壤类型主要为栗钙土。放牧和打 草是该地区主要的土地利用方式。该站点年降水量 $332 \mathrm{~mm}$ (1982-2013年), 其中生长季(5-9月)降水占 全年降水量的 $83 \%$, 主要集中在6-8月。年平均气温 $0.82{ }^{\circ} \mathrm{C}$, 生长季长约 150 天。本研究选择的样地位于 中国科学院内蒙古草原定位研究站羊草样地, 该样 地于 2005年围封并在每年8月中旬左右打草, 植被 类型为典型草原, 优势植物主要有大针茅(Stipa grandis)和羊草(Leymus chinensis)等。样地具体信息 参见表1。

\section{2 研究方法}

\section{1 微气象观测系统}

在两个站点各安装了一套自动气象测定系统, 包括大气温度和相对湿度探头(HMP45C, Campbell Scientific, Logan, USA)测定大气温湿度, 土壤温度 探头(107, Campbell Scientific, Logan, USA)测定不 同深度 $(5 \mathrm{~cm}, 10 \mathrm{~cm}, 20 \mathrm{~cm})$ 的土壤温度, 土壤水分 测定探头(CS616, Campbell Scientific, Logan, USA) 测定表层0-10 $\mathrm{cm}$ 土壤含水量, 水分探头(EasyAG 50, Campbell Scientific, Logan, USA)测定下层 $(10$ $\mathrm{cm}, 20 \mathrm{~cm}, 30 \mathrm{~cm}, 50 \mathrm{~cm}$ ) 土壤含水量, 以及雨量筒 (TE525MM, Campbell Scientific, Logan, USA)测定 降水量, 辐射观测系统(CNR-1, Kipp \& Zonen, Delft, Netherlands)监测生态系统入射和反射辐射, 通过反射辐射与入射辐射的比值计算地表反照率。 微气象站配备数据存储器(CR23X, Campbell Scientific, Logan, USA), 各观测变量每10 s 取样一次, 储 存并输出其30 min的平均值。由于受雨量筒仪器的 测量限制, 无法观测冬季降雪量, 本研究中冬季(11 月到第二年3月)的降雪数据来自 $30 \mathrm{~km}$ 外的多伦县
气象站和 $15 \mathrm{~km}$ 外的中国科学院内蒙古草原定位站 气象观测站。

\section{2 土壤容重和叶面积指数的测定}

土壤容重采用环刀法测定, 分别测定两个站点 0-100 cm不同土层 $(0-5 \mathrm{~cm}, 5-10 \mathrm{~cm}, 10-20 \mathrm{~cm}$, 20-30 cm, 30-50 cm, 50-70 cm, 70-100 cm)的土壤 容重(2011年测定)。叶面积指数( $L A I)$ 采用收割法测 定, 生长季每月进行1-2次。具体而言, 每次在每个 样地取 4 个 $0.5 \mathrm{~m} \times 0.5 \mathrm{~m}$ 的样方, 将地上部分分种收 割, 摘取全部绿色叶片, 通过叶面积仪(LI-3000A, LI-COR, Lincoln, USA)扫描测定其叶面积, 并除以 样方面积换算出LAI (Burba \& Verma, 2005)。

\section{3 降水事件的提取与参数拟合}

根据2006-2013年降水数据, 选择独立的降水 事件, 并对每个降水事件过程中土壤含水量的变化 进行参数拟合。本研究中独立降水事件的篮选条件 为降水发生在一天 $(24 \mathrm{~h})$ 以内, 降水前一天无降水 发生，降水后3天内没有别的降水事件干扰。共篮选 独立降水事件 110 个, 其中多伦共篮选出 59 个独立 降水事件, 降水量变化范围为2.3-39.3 mm, 平均降 水量为 $11.1 \mathrm{~mm}$; 锡林浩特共篮选出 51 个独立降水 事件, 降水量变化范围为1.5-50.5 mm, 平均降水量 为 $12.4 \mathrm{~mm}$ 。

表层0-10 $\mathrm{cm}$ 土壤含水量 $\left(V W C_{0-10}\right)$ 的变化过程 可以用一个指数方程来模拟(Liu et al., 2002):

$$
y=y_{0}+a t \mathrm{e}^{-b t}
$$

其中, $y$ 表示降水发生后不同时间点的 $V W C_{0-10}, y_{0}$ 为 降水前一天的 $V W C_{0-10}\left(V W C_{\mathrm{Pre}}\right), t$ 为降水发生后的 时间, $a$ 和 $b$ 为方程参数(图1)。首先通过曲线拟合求 出 $a$ 和 $b$ 两个参数, 进而计算出降水后 $V W C_{0-10}$ 能够 达到的最大值 $\left(V W C_{\mathrm{Max}}\right)$, 最后求出降水后 $V W C_{0-10}$

表1 多伦和锡林浩特两个研究站点的基本信息

Table 1 General information of Duolun and Xilinhot sites

\begin{tabular}{|c|c|c|c|c|c|c|c|c|c|}
\hline $\begin{array}{l}\text { 站点 } \\
\text { Site }\end{array}$ & $\begin{array}{c}\text { 经纬度 } \\
\text { Longitude and } \\
\text { latitude }\end{array}$ & $\begin{array}{c}\text { 海拔 } \\
\text { Altitude } \\
\text { (m) }\end{array}$ & $\begin{array}{l}\text { 平均年降水量 } \\
\text { Mean annual } \\
\text { precipitation } \\
\text { (mm) }\end{array}$ & $\begin{array}{c}\text { 年平均气温 } \\
\text { Mean annual } \\
\text { temperature } \\
\left({ }^{\circ} \mathrm{C}\right)\end{array}$ & $\begin{array}{l}\text { 土壤类型 } \\
\text { Soil type }\end{array}$ & $\begin{array}{l}\text { 群落高度 } \\
\text { Plant } \\
\text { community } \\
\text { height (cm) }\end{array}$ & $\begin{array}{c}\text { 地上生物量 } \\
\text { Aboveground } \\
\text { biomass }\left(\mathrm{g} \cdot \mathrm{m}^{-2}\right)\end{array}$ & $\begin{array}{l}\text { 优势植物 } \\
\text { Dominant species }\end{array}$ & $\begin{array}{l}\text { 土地利用类型 } \\
\text { Land use type }\end{array}$ \\
\hline $\begin{array}{l}\text { 多伦 } \\
\text { Duolun }\end{array}$ & $\begin{array}{l}42.05^{\circ} \mathrm{N} \\
116.28^{\circ} \mathrm{E}\end{array}$ & 1350 & 380 & 2.2 & $\begin{array}{l}\text { 栗钙土 } \\
\text { Chestnut } \\
\text { soils }\end{array}$ & 42 & 174 & $\begin{array}{l}\text { 冷蒿 } \\
\text { Artemisia frigida } \\
\text { 克氏针茅 } \\
\text { Stipa krylovii }\end{array}$ & $\begin{array}{l}\text { 2001年围封 } \\
\text { Fenced from } \\
2001\end{array}$ \\
\hline $\begin{array}{l}\text { 锡林浩特 } \\
\text { Xilinhot }\end{array}$ & $\begin{array}{l}43.55^{\circ} \mathrm{N}, \\
116.67 \mathrm{E}\end{array}$ & 1250 & 332 & 0.84 & $\begin{array}{l}\text { 栗钙土 } \\
\text { Chestnut } \\
\text { soils }\end{array}$ & 48 & 185 & $\begin{array}{l}\text { 羊草 } \\
\text { Leymus chinensis } \\
\text { 大针茅 } \\
\text { Stipa grandis }\end{array}$ & $\begin{array}{l}\text { 2005年围封并 } \\
\text { 打草 } \\
\text { Fenced and } \\
\text { clipped from } \\
2005\end{array}$ \\
\hline
\end{tabular}




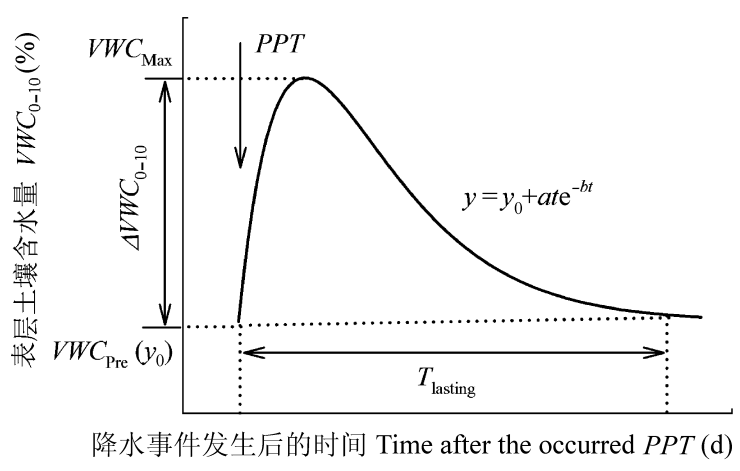

图1 表层0-10 cm土壤含水量 $\left(V W C_{0-10}, y\right)$ 对降水事件的脉 冲响应模式图(参考Liu et al., 2002)。a和 $b$, 方程的参数; PPT,

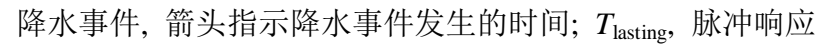
的持续时间(降水后 $V W C_{0-10}$ 高于 $V W C_{\mathrm{Pre}}$ 的时间); $\Delta V W C_{0-10}$, 降水后 $V W C_{0-10}$ 的最大增量; $V W C_{\mathrm{Max}}$, 降水后 $V W C_{0-10}$ 能够达 到的最大值; $V W C_{\text {Pre }}\left(y_{0}\right)$, 降水前一天的 $V W C_{0-10}$ 。

Fig. 1 Conceptual model of the pulse response of surface soil water content $\left(V W C_{0-10}, y\right)$ to precipitation events (refer to Liu et al., 2002). $a$ and $b$, parameters of the equation; PPT, precipitation event, the arrow indicates the time when $P P T$ occurred;

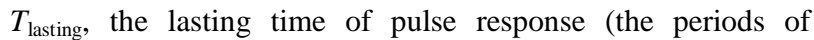
$V W C_{0-10}$ above $V W C_{\text {Pre }}$ after the $\left.P P T\right) ; \triangle V W C_{0-10}$, maximum increment of $V W C_{0-10}$ after the $P P T ; \quad V W C_{\text {Max }}$, maximum $V W C_{0-10}$ after the PPT; $V W C_{\text {Pre }}\left(y_{0}\right), V W C_{0-10}$ of the day before the $P P T$.

的最大增量 $\left(\triangle V W C_{0-10}\right)$, 即 $V W C_{\mathrm{Max}}$ 与 $V W C_{\mathrm{Pre}}$ 之间的 差值。同时, 求出该脉冲响应过程的持续时间 $T_{\text {lasting }}$ (降水后 $V W C_{0-10}$ 高于 $V W C_{\mathrm{Pre}}$ 的时间)。

由于水分下渗的滞后性, 下层 $(10 \mathrm{~cm}, 20 \mathrm{~cm}$, $30 \mathrm{~cm}$ 和 $50 \mathrm{~cm})$ 土壤水分的动态变化过程无法通过 上述指数方程拟合。结合已挑选的降水事件, 用降 水后土壤含水量实际达到的最大值与降水前土壤含 水量的差值来确定该层次土壤含水量的最大增量。 同时, 通过比较不同层次土壤含水量的变化来确定 降水后水分的最大下渗深度(Depth), 比如某次降水 事件发生后, $10 \mathrm{~cm}$ 和 $20 \mathrm{~cm}$ 深处的土壤含水量分别 增加了 $5 \%$ 和 $3 \%$, 而 $30 \mathrm{~cm}$ 和50 $\mathrm{cm}$ 深处的土壤含水 量没有增加(有些还存在下降的过程), 就将该降水 事件的Depth定为 $20 \mathrm{~cm}$ 。将降水事件的Depth除以降 水事件的大小 $(P P T)$ 得到单位降水量的入渗深度 (Depth/PPT)。

\section{4 统计分析}

本文生长季降水和土壤水分的研究时期是每年 的4-10月。表层土壤含水量的脉冲响应过程的拟合 和参数计算通过Matlab 7.1 (The Mathworks, Natick, USA)来实现。采用多元逐步回归分析表层 $\Delta V W C_{0-10}$

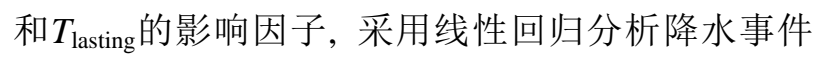

大小对土壤不同层次 $\triangle V W C_{0-10}$ 的影响，采用配对 $t$ 检验比较两个站点不同层次土壤容重的差异, 以上 分析均通过SAS 9.1.3 (SAS Institute, Cary, USA)来 进行。对两个站点之间的 $P P T-\triangle V W C_{0-10}$ 和 $P P T-$ $T_{\text {lasting }}$ 关系的差异分析使用斜率比较软件 Smatr. V2.0 (Falster et al., 2006)进行比较。文中所有作图均 通过SigmaPlot 12.5 (Systat Software, San Jose, USA) 完成。

\section{3 研究结果}

\section{1 降水与土壤含水量的季节与年际变化特征}

研究期间(2006-2013年)多伦和锡林浩特年降 水量分别为 $310.8 \mathrm{~mm}$ 和 $274.5 \mathrm{~mm}$, 其中, 生长季 4-10月降水量分别占年降水总量的 $94 \%$ 和 $91.6 \%$ (图 2)。多伦年平均气温 $2.5{ }^{\circ} \mathrm{C}$, 生长季平均气温 $12.2{ }^{\circ} \mathrm{C}$, 非生长季平均气温 $-11{ }^{\circ} \mathrm{C}$; 锡林浩特年平 均气温 $1.3{ }^{\circ} \mathrm{C}$, 生长季平均气温 $12.1{ }^{\circ} \mathrm{C}$, 非生长季 平均气温 $-13.8{ }^{\circ} \mathrm{C}$ (图2A, 2B)。与该地区雨热同期 相一致的是: 两个站点叶面积指数也在7月份(锡林 浩特)或8月份(多伦)达到峰值(图2C)。对于生长季降 水来说, 两个站点均呈现出干旱年份和湿润年份交 替的规律。其中, 仅多伦2006年生长季降水量423 $\mathrm{mm}$, 锡林浩特2012年生长季降水量412 mm, 高于 两个站点长期生长季降水均值, 其余年份均低于长 期降水均值(图3), 表明本研究期间处于该地区相对 干旱的时期。

伴随着年际间降水量的变化, 生长季平均土壤 含水量呈现显著的年际间波动(图3)。但只有 $V W C_{0-10}$ 与降水量之间存在显著的正相关关系(图 $4 \mathrm{~A}, 4 \mathrm{~B})$ 。其中在锡林浩特站点, 全年降水量对生长 季 $V W C_{0-10}$ 的解释度为 $68 \%(p<0.05)$, 高于生长季 降水量的 $54 \%(p<0.05)$ (图4B)。10-50 cm土层土壤 平均含水量的年际变化与降水量的大小均无显著的 相关关系 $(p>0.05)$ 。

在生长季, 两个站点 $0-30 \mathrm{~cm}$ 土层的土壤含水 量呈现显著的季节波动, 而30-50 cm土层的土壤含 水量的变化幅度显著低于上层土壤, 特别是多伦, 30-50 cm土层的土壤含水量在整个生长季维持相对 稳定。在非生长季, 两站点各层土壤水分都处于冻 结状态(图5)。通过反照率的变化, 发现在春季冻融 时期(3-4月)锡林浩特冬季积雪覆被程度和时间都 明显高于多伦, 两个站点土壤含水量的变化显著不 

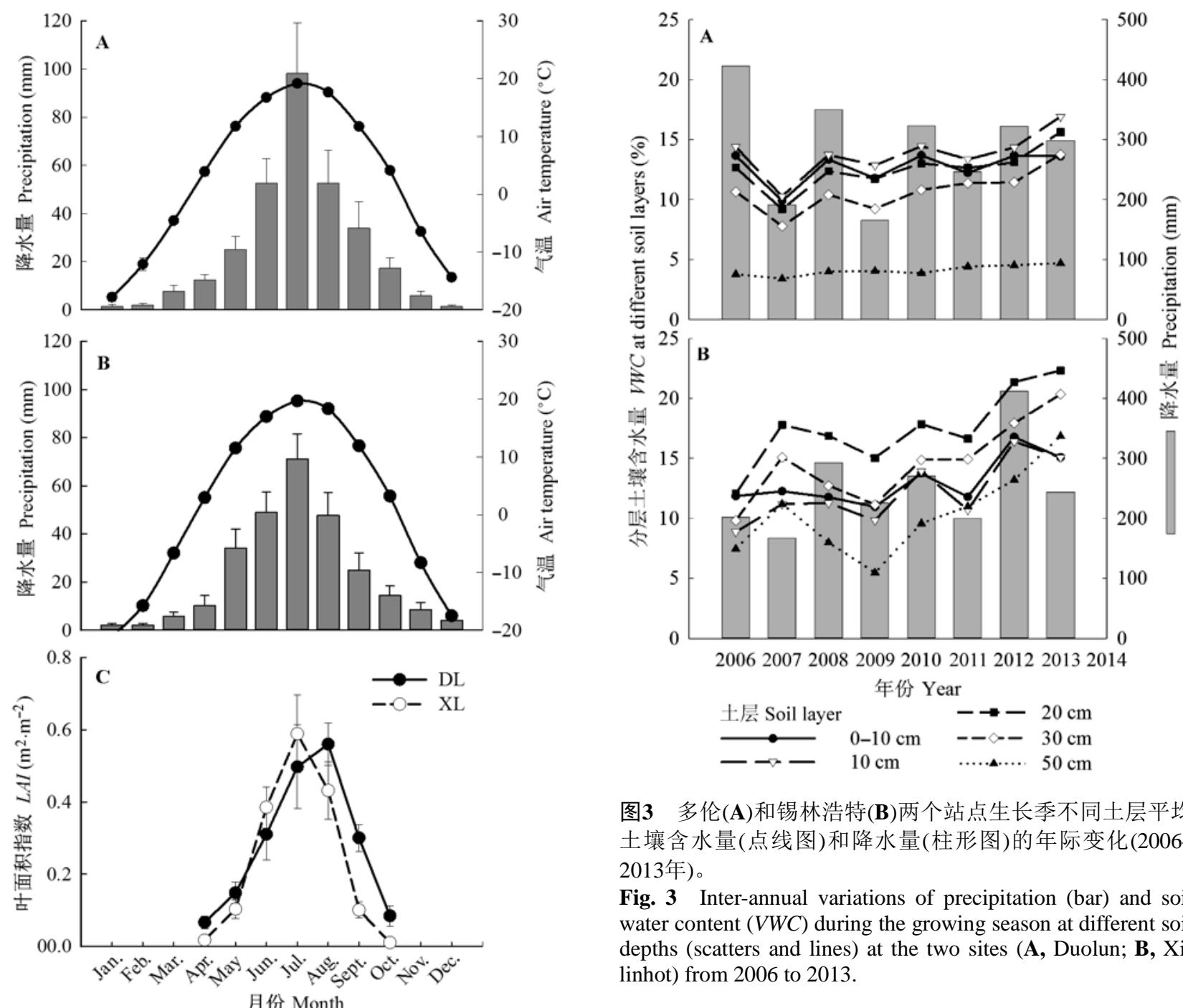

图3 多伦 $(\mathbf{A})$ 和锡林浩特 $(\mathbf{B})$ 两个站点生长季不同土层平均 土壤含水量(点线图)和降水量(柱形图)的年际变化(20062013年)。

Fig. 3 Inter-annual variations of precipitation (bar) and soil water content $(V W C)$ during the growing season at different soil depths (scatters and lines) at the two sites (A, Duolun; B, Xilinhot) from 2006 to 2013.

图2 多伦(DL)和锡林浩特(XL)两个站点8年(2006-2013年) 环境因子和植被因子月均值的动态变化(平均值土标准误差, $n=8)$ 。 $\mathbf{A}$, 多伦平均月降水(柱形图)和气温(折线图)的季节 变化。 B, 锡林浩特平均月降水(柱形图)和气温(折线图)的季 节变化。C, 多伦 (DL) 和锡林浩特 $(\mathrm{XL})$ 月平均叶面积指数 $(L A I)$ 的季节变化。

Fig. 2 Monthly means of environmental and vegetation factors across eight years (2006-2013) at Duolun (DL) and Xilinhot (XL) sites (mean $\pm S E, n=8$ ). A, Seasonal variations of mean monthly precipitation (bar) and air temperature (line) of Duolun. B, Seasonal variations of mean monthly precipitation (bar) and air temperature (line) of Xilinhot. C, Seasonal variations of mean monthly leaf area index (LAI) at Duolun (DL) and Xilinhot (XL).

同(图5)。春季融雪期间，两个站点0-30 cm土层的土 壤含水量均出现了显著升高的过程; 但仅锡林浩特 30-50 cm土层的土壤含水量明显增加, 而多伦30$50 \mathrm{~cm}$ 土层的土壤水分状况并没有发生明显变化。

\section{2 表层土壤含水量对降水事件的响应}

结果显示, $2.3 \mathrm{~mm}$ 和 $1.5 \mathrm{~mm}$ 的降水事件可分别

引起多伦和锡林浩特表层土壤含水量日均值的升 高, 最大增量为 $0.5 \%$ 。多元逐步回归分析表明: 在两 个站点, 降水事件大小 $(P P T)$ 对表层0-10 $\mathrm{cm}$ 土壤含 水量最大增量 $\left(\Delta V W C_{0-10}\right)$ 和持续时间 $\left(T_{\text {lasting }}\right)$ 的变化 均有主导作用 (表2)。在多伦 $P P T$ 能够解释 $\triangle V W C_{0-10}$ $73 \%$ 的变化 $(p<0.001)$, 解释 $T_{\text {lasting }} 43 \%$ 的变化 $(p<$ $0.001)$; 而在锡林浩特, 分别为 $85 \%(p<0.001)$ 和 $65 \%(p<0.001)$ (图6A, 6B)。随着降水事件的增大, $\triangle V W C_{0-10}$ 和 $T_{\text {lasting }}$ 都呈显著增加的趋势, 但 $\triangle V W C_{0-10}$ ( $p=0.972)$ 与 $T_{\text {lasting }}(p=0.853)$ 对 $P P T$ 的响应在两个 站点之间没有显著差异(图6A, 6B)。同时 $\triangle V W C_{0-10}$

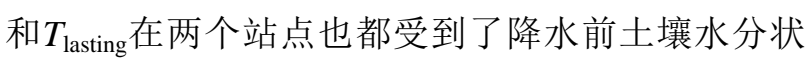

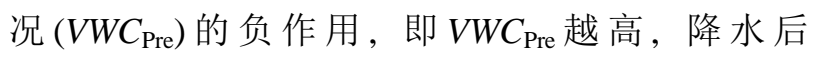
$\triangle V W C_{0-10} / P P T$ 和 $T_{\text {lasting }}$ 越小(图6D, $6 \mathrm{E}$ )。

\section{3 深层土壤含水量对降水事件的响应}

降水后水分会进一步下渗, 两个站点降水后水 
表2 降水后表层土壤含水量最大增量 $\left(\Delta V W C_{0-10}\right)$ 和持续时间 $\left(T_{\text {lasting }}\right)$ 的多元逐步回归分析结果

Table 2 Results of the multiple stepwise regressions on increment of surface soil water content $\left(\Delta V W C_{0-10}\right)$ and lasting time ( $\left.T_{\text {lasting }}\right)$ after the precipitation event at the two sites

\begin{tabular}{|c|c|c|c|c|c|c|c|}
\hline $\begin{array}{l}\text { 因变量 } \\
\text { Variable }\end{array}$ & $\begin{array}{l}\text { 站点 } \\
\text { Site }\end{array}$ & $\begin{array}{l}\text { 进入变量 } \\
\text { Entered variable }\end{array}$ & $\begin{array}{l}\text { 移除变量 } \\
\text { Removed variable }\end{array}$ & $\begin{array}{c}\text { 参数估计 } \\
\text { Parameter estimate }\end{array}$ & $\begin{array}{c}\text { 偏 } R^{2} \\
\text { Partial } R^{2}\end{array}$ & $\begin{array}{c}\text { 模型 } R^{2} \\
\text { Model } R^{2}\end{array}$ & $p$ \\
\hline \multirow[t]{10}{*}{$\triangle V W C_{0-10}$} & 多伦 & 方程截距 Intercept & & 2.32 & & & \\
\hline & Duolun & $P P T$ & & 0.38 & 0.73 & 0.73 & $<0.001$ \\
\hline & & $V W C_{\text {Pre }}$ & & -0.19 & 0.06 & 0.79 & $<0.001$ \\
\hline & & & $S T_{\text {Pre }}$ & -0.08 & 0.00 & 0.79 & 0.282 \\
\hline & & & $L A I$ & 1.30 & 0.00 & 0.79 & 0.340 \\
\hline & 锡林浩特 & 方程截距 Intercept & & 0.92 & & & \\
\hline & Xilinhot & $P P T$ & & 0.35 & 0.52 & 0.85 & $<0.001$ \\
\hline & & $V W C_{\text {Pre }}$ & & -0.08 & 0.08 & 0.01 & 0.084 \\
\hline & & & $S T_{\text {Pre }}$ & 0.01 & 0.00 & 0.86 & 0.820 \\
\hline & & & $L A I$ & 0.58 & 0.00 & 0.86 & 0.356 \\
\hline \multirow[t]{10}{*}{$T_{\text {lasting }}$} & 多伦 & 方程截距 Intercept & & 11.63 & & & \\
\hline & Duolun & $P P T$ & & 0.33 & 0.33 & 0.33 & $<0.001$ \\
\hline & & $V W C_{\text {Pre }}$ & & -0.42 & 0.22 & 0.55 & $<0.001$ \\
\hline & & $S T_{\text {Pre }}$ & & -0.17 & 0.05 & 0.60 & 0.011 \\
\hline & & & $L A I$ & 0.74 & 0.00 & 0.60 & 0.680 \\
\hline & 锡林浩特 & 方程截距 Intercept & & 6.53 & & & \\
\hline & Xilinhot & $P P T$ & & 0.31 & 0.52 & 0.52 & $<0.001$ \\
\hline & & $V W C_{\text {Pre }}$ & & -0.27 & 0.08 & 0.60 & 0.003 \\
\hline & & & $S T_{\text {Pre }}$ & -0.00 & 0.00 & 0.60 & 0.997 \\
\hline & & & $L A I$ & 0.95 & 0.00 & 0.60 & 0.502 \\
\hline
\end{tabular}

自变量包括降水事件大小 $(P P T)$ 、降水前土壤含水量 $\left(V W C_{\mathrm{Pre}}\right)$ 、降水前土壤 $5 \mathrm{~cm}$ 处温度 $\left(S T_{\mathrm{Pr}}\right)$ 和叶面积指数 $(L A I)$ 。

The independent variables included the event size $(P P T)$, soil water content before the event $\left(V W C_{\text {Pre }}\right)$, soil temperature at $5 \mathrm{~cm}$ depth $\left(S T_{\text {Pre }}\right)$ before the event, and leaf area index $(L A I)$.

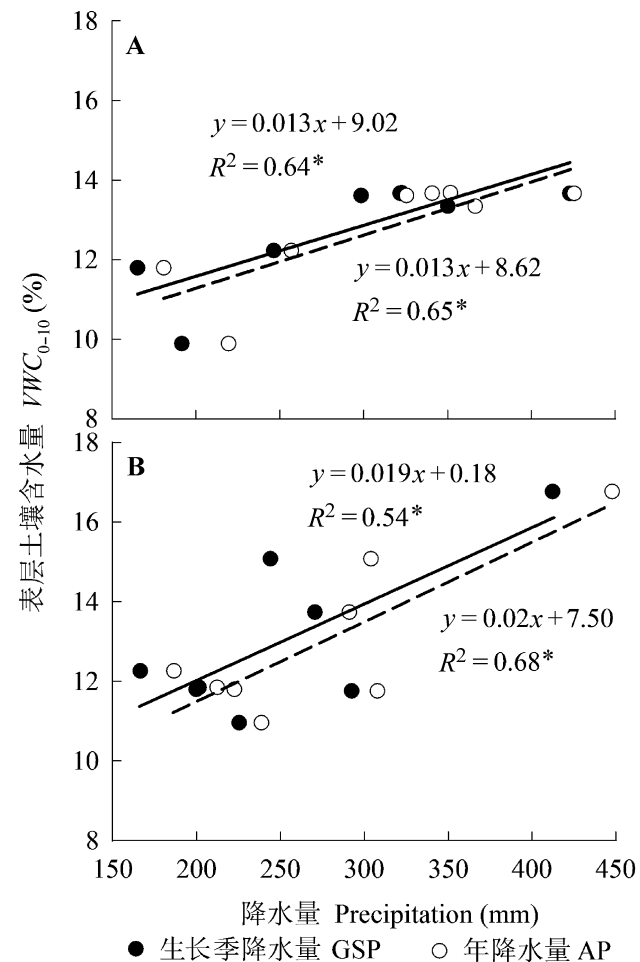

图4 多伦(A)和锡林浩特 $(\mathbf{B})$ 两个站点降水量与生长季平均 表层土壤含水量 $\left(V W C_{0-10}\right)$ 的关系。GSP, 生长季降水量; $\mathrm{AP}$, 年降水量。*, $p<0.05$ 。

Fig. 4 Relationships between surface soil water content $\left(V W C_{0-10}\right)$ and precipitation during the growing season at the two sites (A, Duolun; B, Xilinhot). GSP, the growing season precipitation; AP, annual precipitation. ${ }^{*}, p<0.05$.

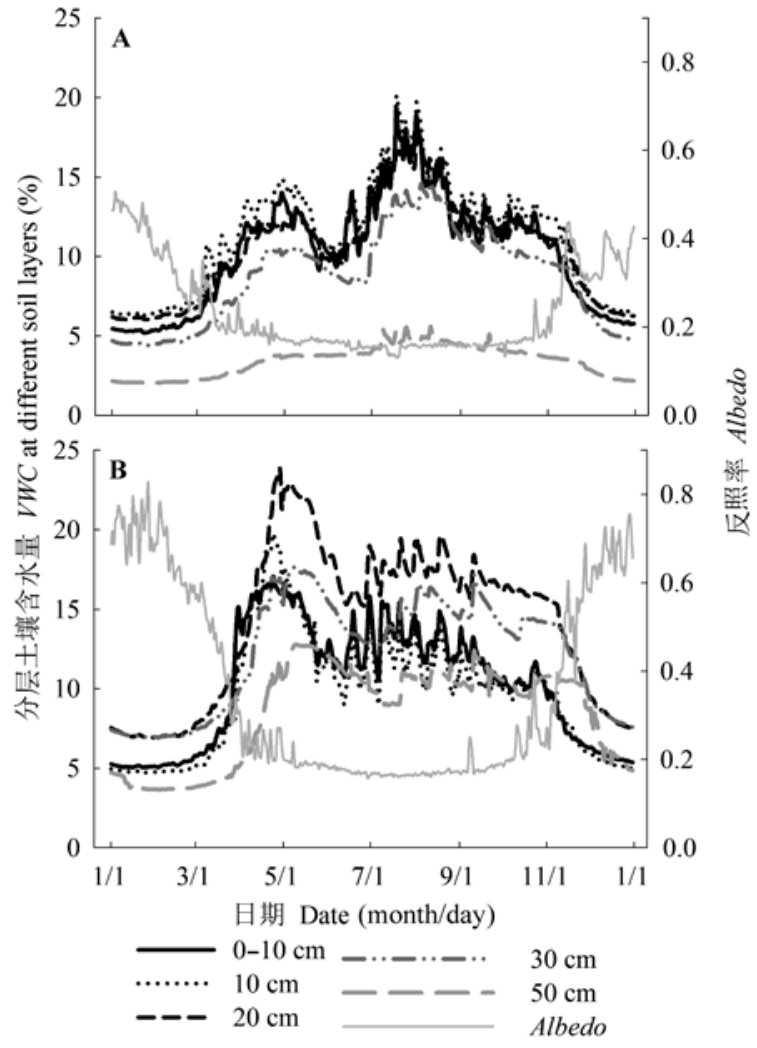

图5 多伦(A)和锡林浩特(B)两个站点不同土层日均土壤含 水量(VWC)与反照率的动态变化(2006-2013年)。

Fig. 5 Seasonal dynamics of mean daily mean soil water content $(V W C)$ at different soil depths and albedo at the two sites (A, Duolun; B, Xilinhot) from 2006 to 2013. 

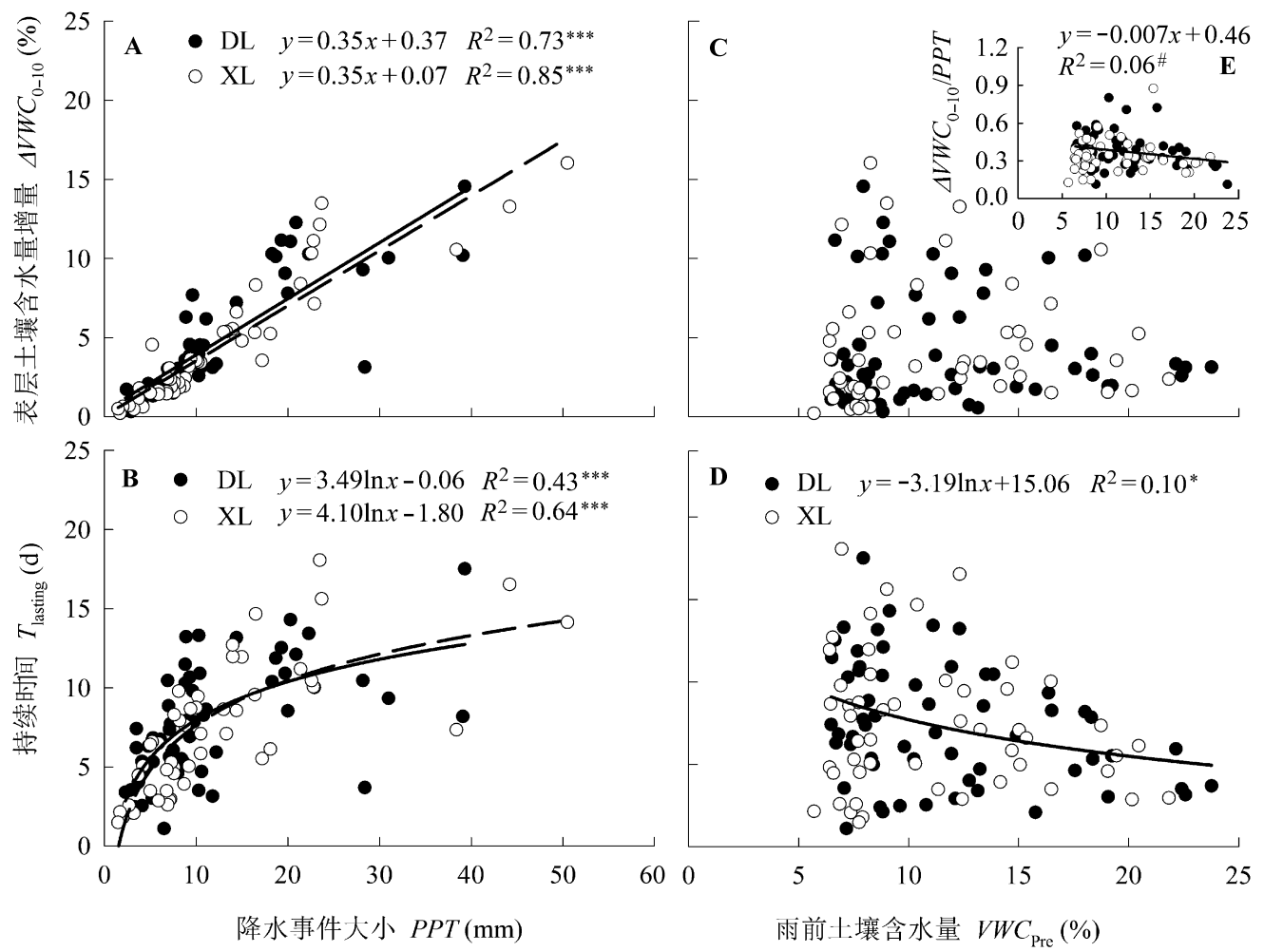

图6 多伦(DL)和锡林浩特 $(\mathrm{XL})$ 两站点降水脉冲响应过程的表层0-10 $\mathrm{cm}$ 土壤含水量最大增量 $\left(\Delta V W C_{0-10}\right)$, 持续时间 $\left(T_{\text {lasting }}\right.$ 和 降水事件大小 $(P P T)$, 降水前土壤含水量 $\left(V W C_{\mathrm{Pre}}\right)$ 之间的关系。 $\mathbf{A}, \triangle V W C_{0-10}$ 和 $P P T$ 的关系。 $\mathbf{B}, T_{\text {lasting }}$ 和 $P P T$ 的关系。 $\mathbf{C}, \Delta V W C_{0-10}$ 和 $V W C_{\mathrm{Pre}}$ 的关系。 $\mathbf{D}, T_{\mathrm{lasting}}$ 和 $V W C_{\mathrm{Pre}}$ 的关系。 $\mathbf{E}$, 单位降水引起的表层土壤水分增量 $\left(\Delta V W C_{0-10} / P P T\right)$ 和 $V W C_{\mathrm{Pre}}$ 的关系。***, $p<$ $0.001 ; *, p<0.050 ; \#, p<0.100$ 。

Fig. 6 Relationships of the maximum increment of surface $0-10 \mathrm{~cm}$ soil water content $\left(\Delta V W C_{0-10}\right)$ and lasting time $\left(T_{\text {lasting }}\right)$ in the pulse response process to precipitation with precipitation event size $(P P T)$ and soil moisture content before precipitation events $\left(V W C_{\mathrm{Pre}}\right)$ at the two sites (DL, Duolun; XL, Xilinhot). A, Relationship between $\triangle V W C_{0-10}$ and $P P T$. B, Relationship between $T_{\text {lasting }}$ and PPT. C, Relationship between $\triangle V W C_{0-10}$ and $V W C_{\text {Pre. }}$. D, Relationship between $T_{\text {lasting }}$ and $V W C_{\text {Pre. }}$ E, Relationship between the maximum increment of $\triangle V W C_{0-10}$ induced by $1 \mathrm{~mm}$ precipitation and $V W C_{\text {Pre }}{ }^{* * *}, p<0.001 ; *, p<0.050 ; \#, p<0.100$.
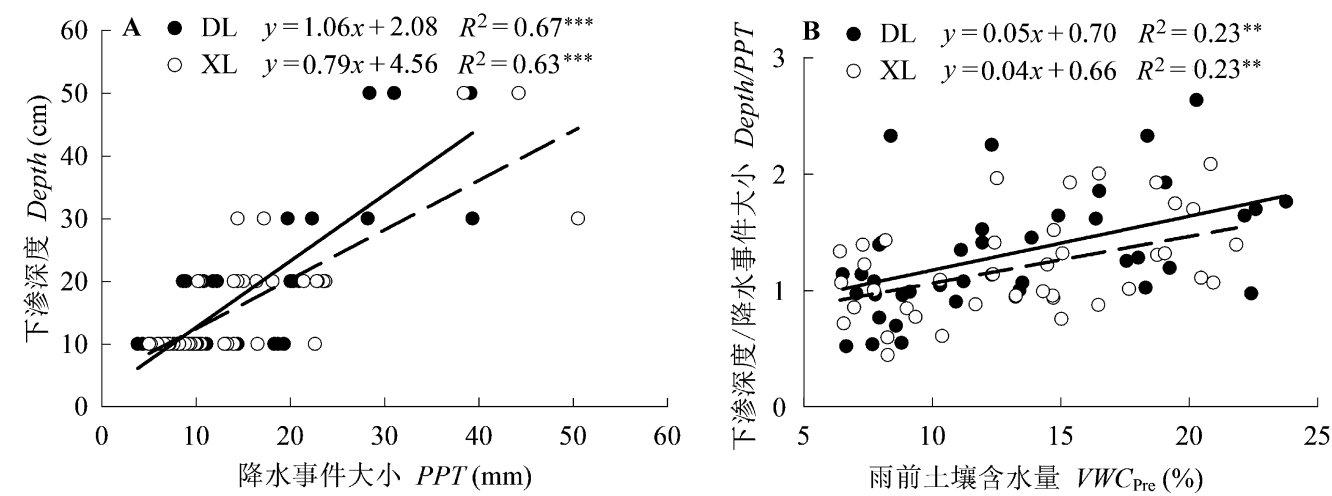

图7 多伦 $(\mathrm{DL})$ 和锡林浩特 $(\mathrm{XL})$ 两站点降水后土壤水分下渗深度(Depth)与降水事件大小 $(P P T)$ 及降水前土壤含水量 $\left(V W C_{\mathrm{Pre}}\right)$ 的关系。A, Depth与 $P P T$ 的关系。 $\mathbf{B}$, 单位降水入渗深度 $($ Depth $/ P P T)$ 与 $V W C_{\mathrm{Pre}}$ 的关系。***, $p<0.001 ; * *, p<0.010$ 。

Fig. 7 Relationships between infiltration depth (Depth) with precipitation event size (PPT) and soil water content before the events $\left(V W C_{\mathrm{Pre}}\right)$ at the two sites (DL, Duolun; XL, Xilinhot). A, Relationship between Depth and PPT. B, Relationship between infiltration depth of $1 \mathrm{~mm}$ precipitation (Depth/PPT) and $V W C_{\text {Pre. }} * * *, p<0.001 ; * *, p<0.010$.

分的最大下渗深度(Depth)与 $P P T$ 呈显著的正相关关 系, PPT分别能够解释多伦和锡林浩特Depth的 $67 \%$ $(p<0.001)$ 和63\% $(p<0.001)$ (图7A)。降水量平均每
增加 $1 \mathrm{~mm}$, 下渗深度在多伦和锡林浩特分别增加 $1.06 \mathrm{~cm}$ 和 $0.79 \mathrm{~cm}$ (图7A)。同时, $V W C_{\mathrm{Pre}}$ 也是影响土 壤水分下渗的重要因素, 表现为 $V W C_{\mathrm{Pre}}$ 越高, 单位

www.plant-ecology.com 
表3 不同土层降水后土壤水分增量 $(y, \%)$ 与降水事件大小 $(x, \mathrm{~mm})$ 的线性回归分析结果(包括回归方程, $R^{2}$ 和 $p$ 值)

Table 3 Results of linear regression (including equation, $R^{2}$ and $p$ value) between precipitation event size $(x, \mathrm{~mm})$ and the increment of soil water content $\underline{(y, \%) \text { at different soil depth }}$

\begin{tabular}{|c|c|c|c|c|c|c|c|c|}
\hline \multirow{2}{*}{$\begin{array}{l}\text { 土层 } \\
\text { Soil layer (cm) }\end{array}$} & \multicolumn{4}{|c|}{ 多伦 Duolun } & \multicolumn{4}{|c|}{ 锡林浩特 Xilinhot } \\
\hline & $\begin{array}{c}\text { 方程 } \\
\text { Equation }\end{array}$ & $\begin{array}{c}\text { 样本量 } \\
\text { No. of samples } \\
\end{array}$ & $R^{2}$ & $p$ & $\begin{array}{c}\text { 方程 } \\
\text { Equation }\end{array}$ & $\begin{array}{c}\text { 样本量 } \\
\text { No. of samples } \\
\end{array}$ & $R^{2}$ & $p$ \\
\hline 10 & $y=0.31 x-0.37$ & 40 & 0.54 & $<0.0001$ & $y=0.39 x-0.91$ & 40 & 0.72 & $<0.0001$ \\
\hline 20 & $y=0.20 x+0.44$ & 14 & 0.34 & 0.0298 & $y=0.34 x-3.45$ & 17 & 0.67 & $<0.0001$ \\
\hline 30 & $y=0.38 x-7.56$ & 7 & 0.77 & 0.0094 & $y=0.27 x-4.12$ & 5 & 0.77 & 0.0513 \\
\hline
\end{tabular}

降水的下渗深度 $($ Depth/PPT) 越大 $(p<0.01)$ (图7B)。 分析显示: 在多伦和锡林浩特, PPT分别能解释土 壤 $10 \mathrm{~cm}$ 深处含水量增量的 $54 \%(p<0.001)$ 和 $72 \%(p$ $<0.001)$; 解释 $20 \mathrm{~cm}$ 深处土壤含水量增量的 $34 \%(p$ $<0.05)$ 和 $67 \%(p<0.001)$; 两个站点 $30 \mathrm{~cm}$ 深处土壤 含水量增量均能被PPT解释 $77 \%(p=0.0094, p=$ 0.0513 ) (表3)。由于能下渗至 $50 \mathrm{~cm}$ 处的降水事件在 两个站点较少 $(n \leqslant 3)$, 故而未作相关分析。尽管在 不同层次 PPT对土壤含水量增量的解释度在两个站 点有所差异, 但并未发现两个站点不同层次土壤含 水量增量对 $P P T$ 的响应关系存在显著差别(表3)。

\section{4 讨论}

\section{1 降水量季节和年际变化对土壤含水量的影响}

本研究中, 我们发现伴随着降水量的年内年际 间变化, 各层土壤含水量也呈现出显著的变化, 但 在年际间只有表层土壤含水量跟降水量呈现出显著 的相关关系。这是因为尽管土壤含水量直接决定于 降水量, 但同时也会受到降水格局变化的影响。以 往的研究发现在不改变降水总量的情况下, 降水间 隔的延长可以显著升高干旱地区的土壤含水量 (Heisler-White et al., 2009), 而降低湿润生态系统的 土壤含水量(Knapp et al., 2002; Heisler-White et al., 2009)。同时生长季土壤含水量还会受到非生长季降 雪的影响, 但这个影响在多伦站点并不明显; 而在 锡林浩特站点, 年降水量对生长季土壤含水量的解 释度(68\%)显著高于生长季降水量(54\%)。这是由于 冬季锡林浩特的大量积雪在春季集中融化, 进而对 土壤含水量产生相对持久的影响; 而多伦由于气温 相对较高, 很少有雪累积下来, 因而冬季降雪对生 长季水分状况并没有比较明显的影响。

\section{2 降水事件对土壤含水量的影响}

土壤水分变化对降水事件的响应是一个非常复 杂的过程, 因为该过程不仅受降水事件大小的主导
(Heisler-White et al., 2008), 还受到降水强度(Yaseef et al., 2010)、干旱期长短、植被类型和土壤质地 (Miller et al., 1983)等的影响。

一般小降水事件发生后, 由于植被冠层截留和 调落物层的影响, 降水很少能被土壤吸收, 那么, 多大的降水才能透过冠层和调落物对土壤和植被生 长产生影响呢? 这就涉及有效降水的界定。针对不 同的研究目的, 研究人员得出了不同的有效降水的 定义与大小。Coupland (1950)认为对于干旱半干旱 地区，大于 $8-10 \mathrm{~mm}$ 的降水事件才能算作有效降水; 但也有一些研究认为小降水事件对干旱生态系统也 至关重要(Sala \& Lauenroth, 1982; Loik et al., 2004; Ryel et al., 2004)。小降水事件可以通过湿润土壤表 面及增加大气湿度来缓解植物的干旱胁迫, 增加其 在干旱环境中的存活几率, 进而在大降水事件来临 时使其能够迅速激活并生长(Huxman et al., 2004)。 在本研究区域, 郝彦宾(2006)和苗海霞(2008)分别 基于降水对生态系统碳通量和蒸发散的影响认为在 内蒙古半干旱草原大于 $3 \mathrm{~mm}$ 的降水为有效降水。

本研究发现 $2.3 \mathrm{~mm}$ 和 $1.5 \mathrm{~mm}$ 的降水就能够促 进多伦和锡林浩特表层土壤含水量的增加。因此, 我们认为大于 $2 \mathrm{~mm}$ 的日降水量在内蒙古半干旱草 原具有湿润表层土壤的作用, 进而可将其作为该地 区生态系统的有效降水量, 这一结果与 Heisler-White等(2008)的研究结果一致。但在分析中 我们也发现一些大于 $2 \mathrm{~mm}$ 的降水有时并未引起土 壤含水量的变化, 这主要跟降水的强度和发生时间 有关。 $2 \mathrm{~mm}$ 的降水集中发生和分散发生被冠层截留 掉的比例是不一样的。在生长季旺季, 植被盖度较 高也会截留相对较多的雨水, 从而导致降水的有效 性降低。大的降水事件能够影响到深层的土壤, 本 研究中 $30 \mathrm{~mm}$ (多伦)和 $40 \mathrm{~mm}$ (锡林浩特)的降水能 够下渗到 $50 \mathrm{~cm}$ 处并对土壤水分产生有效的补给。针 对小降水事件减少而大降水事件增加的影响的研究 
是当前降水格局变化研究的重要内容之一(Knapp et al., 2008)。小降水减少将导致降水间隔增加, 而使 得表层土壤更加频繁、长期地处于干旱状况, 而大 降水事件的增加会促进更多水分下渗到深层土壤 (Huxman et al., 2004, Thomey et al., 2011), 这种表 层和深层土壤水分不同的变化可能会进一步导致生 态系统结构和功能的改变(Huxman et al., 2004)。在 北美一个湿润的高草草原上的研究发现延长降水间 隔引起的大降水事件的增加促进了物种的多样性, 主要是因为稀有种类的增加(Knapp et al., 2002)。研 究也发现在干旱半干旱地区, 减少小降水事件、增 加大降水事件会显著增加土壤水分的可利用性, 进 而促进生态系统的生产力(Schwinning \& Sala, 2004; Heisler-White et al., 2009; Thomey et al., 2011; Wilcox et al., 2015), 在湿润地区则相反(Knapp et al., 2002; Heisler-White et al., 2009)。不同的生态系 统对降水格局变化响应的差异与植物的根系分布相 关。在干旱生态系统植物根系分布较深, 而在湿润 生态系统根系分布较浅(Schenk \& Jackson, 2005), 深根系统对深层水分的变化响应较强, 而浅根植物 更容易受到表层干旱的抑制。

本研究表明不同层次土壤含水量的增量与降水 强度显著正相关, 而干旱期长短也会影响土壤含水 量对降水事件的响应。干旱期长短表现在降水前土 壤含水量的高低, 本研究发现降水前土壤含水量越 低, 土壤含水量对降水事件的响应就越大(更大的 $\left.\triangle V W C_{0-10} / P P T\right)$ 。降水前含水量越高, 降水后表层土 壤水分增加的潜力也越小, 水分下渗的速度和深度 就会增加。此外, 一个地区的植被类型在水分的再 分配和蒸发散的过程中扮演重要角色, 进而也会影 响到土壤水分的动态(Ryel et al., 2004; Oki \& Kanae, 2006)。但是在多元逐步回归分析中并未发现 植被叶面积指数对土壤水分的脉冲过程的显著影 响。研究发现多伦和锡林浩特土壤水分对降水事件 的响应没有差异 $\left(\Delta V W C_{0-10}\right.$ 和 $\left.T_{\text {lasting }}\right)$, 原因可能在于 两个地方都是典型草原, 拥有相似的植被类型且群 落高度和生物量比较接近(表1), 生长季最大LAI也 很接近(图2C)。与锡林浩特站点相比, 多伦单位降 水量的增加能够在土壤中下渗更深, 这主要跟两个 站点的土壤质地、地形和土地利用类型有关。多伦 站点地处河滩, 土壤容重较大(图8), 且土壤中石砾 含量较多, 较小的土壤孔隙度会增加土壤水分的下

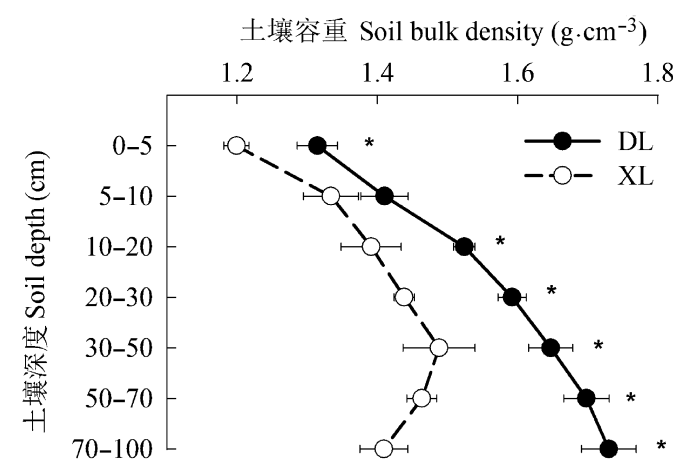

图8 多伦 $(\mathrm{DL})$ 和锡林浩特 $(X L)$ 两站点土壤容重垂直分布 $(0-100 \mathrm{~cm})$ 。 *表示两个站点之间存在显著差异 $(p<0.050$, $n=5)$ 。

Fig. 8 Vertical distributions of soil bulk density $(0-100 \mathrm{~cm})$ at the two sites (DL, Duolun; XL, Xilinhot). * indicates significant difference between the two sites at $p<0.050(n=5)$.

渗深度。同时，相比于地处缓坡 $\left(3^{\circ}-4^{\circ}\right)$ 且每年打草 的锡林浩特站点, 多伦站样地为长期围封样地且地 势平坦, 累积较多的调落物, 也有助于降水时雨水 的保持及下渗。

\section{5 结论}

降水量的季节和年际变化显著影响多伦和锡林 浩特草原 $0-30 \mathrm{~cm}$ 土层的土壤含水量, 而对 $30 \mathrm{~cm}$ 以 下更深土层土壤含水量的影响较小。在锡林浩特站 点, 30-50 cm 土层的土壤含水量受春季融雪的影 响大。

多伦和锡林浩特土壤含水量对降水事件的脉冲 响应没有显著差异。降水事件大小和降水前土壤水 分状况是影响表层土壤含水量对降水事件脉冲响应 过程的最重要影响因素, 大的降水事件能引起土壤 含水量更强脉冲响应(较大的土壤水分增量和响应 持续时间)。土壤水分的下渗深度及该深度层次的土 壤含水量增量主要由降水事件大小主导，同时受降 水前表层土壤含水量的影响。在多伦和锡林浩特, 平均每增加 $1 \mathrm{~mm}$ 降水, 下渗深度分别增加 1.06 和 $0.79 \mathrm{~cm}$ 。由此, 在内蒙古半干旱草原, 降水事件大 小和降水前土壤干湿状况是影响土壤水分对降水响 应的主要因素, 而植被因子的影响相对较小。未来 在研究生态系统对降水事件响应的过程中, 不仅需 要考虑降水事件的大小, 而且不能忽略降水前干湿 状况即干旱间隔的影响。

基金项目 国家自然科学基金面上项目(31170453) 
和中国科学院战略性先导科技专项-应对气候变化 的碳收支认证及相关问题(XDA05050402)。

\section{参考文献}

Adams JM, Faure H, Fauredenard L, Mcglade JM, Woodward FI (1990). Increases in terrestrial carbon storage from the last glacial maximum to the present. Nature, 348, 711714.

Blair JM (1997). Fire, $\mathrm{N}$ availability, and plant response in grasslands: A test of the transient maxima hypothesis. Ecology, 78, 2359-2368.

Burba GG, Verma SB (2005). Seasonal and interannual variability in evapotranspiration of native tallgrass prairie and cultivated wheat ecosystems. Agricultural and Forest Meteorology, 135, 190-201.

Chen SP, Lin GH, Huang JH, Jenerette GD (2009). Dependence of carbon sequestration on the differential responses of ecosystem photosynthesis and respiration to rain pulses in a semiarid steppe. Global Change Biology, 15, 2450-2461.

Chen ZZ, Wang SP (2000). Typical Steppe Ecosystems of China. Science Press, Beijing. (in Chinese) [陈佐忠, 汪诗平 (2000). 中国典型草原生态系统. 科学出版社, 北京.]

Coupland RT (1950). Ecology of mixed prairie in Canada. Ecological Monograph, 20, 271-315.

Easterling DR, Meehl GA, Parmesan C, Changnon SA, Karl TR, Mearns LO (2000). Climate extremes: Observations, modeling, and impacts. Science, 289, 2068-2074.

Falster DS, Warton DI, Wright IJ (2006). SMATR: Standardised major axis tests and routines, ver 2. 0. http://www.bio. mq.edu.au/ecology/SMATR/. Cited: 11 Mar. 2006.

Fay PA, Blair JM, Smith MD, Nippert JB, Carlisle JD, Knapp AK (2011). Relative effects of precipitation variability and warming on tallgrass prairie ecosystem function. Biogeosciences, 8, 3053-3068.

Groisman PY, Karl TR, Easterling DR, Knight RW, Jamason PF, Hennessy KJ, Suppiah R, Page CM, Wibig J, Fortuniak K, Razuvaev VN, Douglas A, Førland Eirik, Zhai PM (1999). Changes in the probability of heavy precipitation: Important indicators of climatic change. Climatic Change, 42, 243-283.

Hao YB (2006). Characteristics of Net Ecosystem Exchange of Carbon Dioxide and Their Driving Factors over a Fenced Leymus chinensis Steppe in Inner Mongolia. PhD dissertation, Institute of Botany, Chinese Academy of Sciences, Beijing. 115-117. (in Chinese with English abstract) [郝彦 宾 (2006). 内蒙古羊草草原碳通量观测及其驱动机制 分析. 博士学位论文, 中国科学院植物研究所, 北京. 115-117.]

Harper CW, Blair JM, Fay PA, Knapp AK, Carlisle JD (2005). Increased rainfall variability and reduced rainfall amount decreases soil $\mathrm{CO}_{2}$ flux in a grassland ecosystem. Global Change Biology, 11, 322-334.
Heisler-White JL, Blair JM, Kelly EF, Harmoney K, Knapp AK (2009). Contingent productivity responses to more extreme rainfall regimes across a grassland biome. Global Change Biology, 15, 2894-2904.

Heisler-White JL, Knapp AK, Kelly EF (2008). Increasing precipitation event size increases aboveground net primary productivity in a semi-arid grassland. Oecologia, 158, 129-140.

Huxman TE, Snyder KA, Tissue D, Leffler AJ, Ogle K, Pockman WT, Sandquist DR, Potts DL, Schwinning S (2004). Precipitation pulses and carbon fluxes in semiarid and arid ecosystems. Oecologia, 141, 254-268.

IPCC (Intergovernmental Panel on Climate Change) (2013). Climate Change 2013: The Physical Science Basis. Contribution of Working Group I to the Fifth Assessment Report of the Intergovernmental Panel on Climate Change. Cambridge University Press, New York.

Knapp AK, Beier C, Briske DD, Classen AT, Luo YQ, Reichstein M, Smith MD, Smith SD, Bell JE, Fay PA, Heisler JL, Leavitt SW, Sherry R, Smith B, Weng E (2008). Consequences of more extreme precipitation regimes for terrestrial ecosystems. Bioscience, 58, 811-821.

Knapp AK, Fay PA, Blair JM, Collins SL, Smith MD, Carlisle JD, Harper CW, Danner BT, Lett MS, McCarron JK (2002). Rainfall variability, carbon cycling, and plant species diversity in a mesic grassland. Science, 298, 22022205.

Knapp AK, Smith MD (2001). Variation among biomes in temporal dynamics of aboveground primary production. Science, 291, 481-484.

Liu XZ, Wan SQ, Su B, Hui DF, Luo YQ (2002). Response of soil $\mathrm{CO}_{2}$ efflux to water manipulation in a tallgrass prairie ecosystem. Plant and Soil, 240, 213-223.

Loik ME, Breshears DD, Lauenroth WK, Belnap J (2004). A multi-scale perspective of water pulses in dryland ecosystems: Climatology and ecohydrology of the western USA. Oecologia, 141, 269-281.

Miao HX (2008). Effects of Cultivation and Grazing on Evapotranspiration of Steppe Ecosystems in Inner Mongolia, China. PhD dissertation, Institute of Botany, Chinese Academy of Sciences, Beijing. 62-74. (in Chinese with English abstract) [苗海霞 (2008). 开艮和放牧对内蒙古 半干旱草原蒸发散的影响. 博士学位论文, 中国科学院 植物研究所, 北京. 62-74.]

Miller PC, Poole DK, Miller PM (1983). The Influence of annual precipitation, topography, and vegetative cover on soil moisture and summer drought in Southern California. Oecologia, 56, 385-391.

Ni J, Zhang XS (2000). Climate variability, ecological gradient and the Northeast China Transect (NECT). Journal of Arid Environments, 46, 313-325.

Oki T, Kanae S (2006). Global hydrological cycles and world 
water resources. Science, 313, 1068-1072.

Potts DL, Huxman TE, Cable JM, English NB, Ignace DD, Eilts JA, Mason MJ, Weltzin JF, Williams DG (2006). Antecedent moisture and seasonal precipitation influence the response of canopy-scale carbon and water exchange to rainfall pulses in a semi-arid grassland. New Phytologist, 170, 849-860.

Ryel RJ, Leffler AJ, Peek MS, Ivans CY, Caldwell MM (2004). Water conservation in Artemisia tridentata through redistribution of precipitation. Oecologia, 141, 335-345.

Sala OE, Lauenroth WK (1982). Small rainfall events: An ecological role in semiarid regions. Oecologia, 53, 301-304.

Schenk HJ, Jackson RB (2005). Mapping the global distribution of deep roots in relation to climate and soil characteristics. Geoderma, 126, 129-140.

Schwinning S, Sala OE (2004). Hierarchy of responses to resource pulses in arid and semi-arid ecosystems. Oecologia, 141, 211-220.

Thomey ML, Collins SL, Vargas R, Johnson JE, Brown RF, Natvig DO, Friggens MT (2011). Effect of precipitation variability on net primary production and soil respiration in a Chihuahuan Desert grassland. Global Change Biology, 17, 1505-1515.

Weltzin JF, Tissue DT (2003). Resource pulses in arid envi- ronments-patterns of rain, patterns of life. New Phytologist, 157, 171-173.

Westra S, Fowler HJ, Evans JP, Alexander LV, Berg P, Johnson F, Kendon EJ, Lenderink G, Roberts NM (2014). Future changes to the intensity and frequency of shortduration extreme rainfall. Reviews of Geophysics, 52, 522-555.

Wilcox KR, von Fischer JC, Muscha JM, Petersen MK, Knapp AK (2015). Contrasting above- and belowground sensitivity of three great plains grasslands to altered rainfall regimes. Global Change Biology, 21, 335-344.

Williams CA, Hanan N, Scholes RJ, Kutsch W (2009). Complexity in water and carbon dioxide fluxes following rain pulses in an African savanna. Oecologia, 161, 469-480.

Yahdjian L, Sala OE (2006). Vegetation structure constrains primary production response to water availability in the Patagonian steppe. Ecology, 87, 952-962.

Yaseef NR, Yakir D, Rotenberg E, Schiller G, Cohen S (2010). Ecohydrology of a semi-arid forest: Partitioning among water balance components and its implications for predicted precipitation changes. Ecohydrology, 3, 143-154.

责任编委: 梁存柱 责任编辑: 王 葳

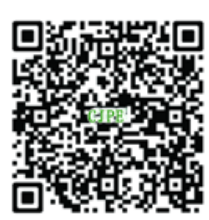

植物生态学报官网

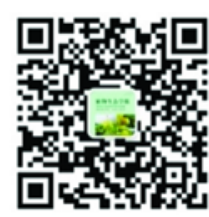

微信订阅号

期刊及学科

相关信息发布

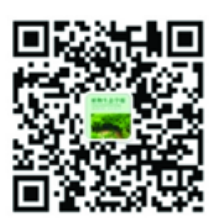

微信服务号

稿件状态查询 全文检索汶览 